\title{
On the Meaning of Beautiful China \& Its Construction
}

\author{
Xianbiao $\mathrm{Ma}^{1, *}$, Yi Li ${ }^{2}$, Chuanru $\mathrm{Gao}^{2}$, Zhijian Liang ${ }^{3}$
}

\author{
${ }^{1}$ GuiZhou University, GuiZhou, China \\ ${ }^{2}$ Qinghai Nationalities University, Qinghai, China \\ ${ }^{3}$ Qinghai University, Qinghai, China \\ *Corresponding author
}

\begin{abstract}
In recent years, the ecological crisis, represented by the widespread smog, has placed before us the urgent strategic task of protecting the ecological environment, building ecological civilization and realizing a Beautiful China. This requires first to understand the meaning of the concept on Beautiful China. Thereafter, we should build a related institutional framework according to system engineering thought, and integrate it into the economic, political, social, and culture field. In addition, the Communist Party, the government and the broad masses of the people under their leadership are the main body in building a Beautiful China.
\end{abstract}

Keywords: Beautiful China, Concept's meaning, Ecological civilization, Institution frame and system engineering, Construction path

\section{INTRODUCTION}

As you can see, apart from the previous extensive economic growth and the overexploitation of resources, unhealthy and irrational lifestyle and consumptive behavior have jointly led to various environmental pollution incidents which continually become irreversible nearly. Besides the above, in recent years, the ecological crisis, represented by the widespread smog, has placed before us the important-urgent strategic task of protecting the ecological environment, building an ecological civilization and thus realizing a Beautiful China. Moreover, such task is embodied through the high pressure of alarm bells and signature of military writs in front of the whole Party and people.

Undoubtedly, the goal of ecological civilization construction is Beautiful China. It can be said that the significance of constructing an ecological civilization and the construction of Beautiful China, including its importance, necessity and urgency, has been fully recognized by the academic circle, including the practical circle. The general public also has intuitive feelings and consensus.

However, we still have at least two more critical issues which we presently have not yet understood and grasped well: First, what is a Beautiful China? And the rigorous academic title is just about the meaning of a Beautiful China; Second, after understanding the basic meaning of Beautiful China, it is then necessary to answer the question of how to build up the relevant system or policy system of Beautiful China.

\section{WHAT IS A BEAUTIFUL CHINA?}

In fact, this question is what kind of Beautiful China we should build. It also includes the content elements of the Beautiful China, and the "overall image" itself. With no doubt, they are two sub-propositions closely related.

To better understand the problem of "what is a Beautiful China" and related sub-propositions, my understanding thinking and approaches are as followed:

On one hand, from the perspective of "beauty" and "China", we can analyze the overall meaning of Beautiful China. From the literal point of view, beauty means good and harmony. A few dictionary tools also interpret beauty as a good and gorgeous thing.

However, it is not difficult to find that when it comes to the specific field of ecological protection, ecological civilization and the construction of a Beautiful China, the beauty here may mainly mean beauty and harmony. In this way, the meaning of Beautiful China is the meaning of a beautiful and harmonious China. It answers the sub-proposition of what kind of "overall image" about the Beautiful China to be built from an abstract angle.

On the other hand, we need to understand how to make China harmonious and beautiful in which aspect or area. As mentioned before, there is no doubt that the overall goal of the construction on ecological civilization is the Beautiful China. Furthermore, from the historical background and fundamental cause of the strategic task of the Beautiful China, we can draw the following conclusion: Beautiful China is mainly focused in the field of ecological environment to make China beautiful and harmonious gradually. In other words, we should promote China's ecological environment beautiful.

In the past time, in the process of extensive economic growth, many regions have adhered to the working philosophy of pollution first and treatment later, leading to ecological crises such as water pollution, soil pollution, air pollution, heavy metal pollution, and land desertification. Even though a wide range of high-intensity smog weather continues in these regions. To a considerable extent, this 
has made the Chinese ecological environment not so good and harmonious, not so beautiful as well. More seriously, it has affected the people's production and living order, including property security and life security.

Therefore, it is necessary to firmly establish and implement the Scientific Outlook on Development, striving to find the rooted causes of the above mentioned ecological environment disharmony, and then formulate and implement effective institutional arrangements or policies. To clean up the water, clean up the air, make the sky blue, make the earth green and so on, may become our comrade's theoretical and practical work. Naturally, they require us to focus on recognizing and grasping the intuitive and visual main areas, key contents, and basic elements of a Beautiful China. It answers another sub-proposition composed of the content elements of Beautiful China itself and where the beauty is.

So far, we can naturally combine the above brief answers to the two sub-propositions, and we can make a brief interpretation of what constitutes a Beautiful China: that is, the overall image of a Beautiful China and the overall goal of its construction are making the ecological environment beautiful and harmonious within the vast territory of our motherland. Specifically, it means adopting effective institutional arrangements or policies to protect people's production order, quality of life, property and even life safety after finding out rooted causes of ecological environment pollution currently. In these key ecological environment areas, we make more progress and stimulate the whole good and harmony of china. In the end, we form and strive to maintain clean water, clean air, blue sky, green land all over the country.

Here, it needs to be pointed out that there are many other perspectives on the composition of the specific content or elements of a Beautiful China. Undoubtedly, they are also of positive significance for enriching relevant theories and doing relevant practical work. For example, from the perspective of geographical space or administrative jurisdiction, China needs to be beautiful, and many provinces or cities in the east, west, north and south should be beautiful. The ecological environment in these provinces or cities should be beautiful and harmonious. The provincial and municipal party committees and governments naturally need to keep the caretaker duty and fulfill related mission in order to jointly support the construction of Beautiful China.

Of course, "ShanShuiLinTianHu" is a community of life. If we understand it from the perspective of ecosystem theory, we can also expand the path of understanding the Beautiful China. For example, China's mountains, waters, plain plateaus, marsh wetlands, grassland and woodland crops, etc., should all become beautiful and harmonious. Specific to the various provincial administrative regions, such as Jiangxi province or Guizhou province, the constituent elements and understanding logic of the beautiful province are generally the same. I have also noticed that some key universities in China have successively established research institutions for "Beautiful China", "beautiful provinces and cities", and worked hard to interpret them.
However, we should be soberly aware that since the meaning of a Beautiful China comes from many perspectives, we also need colleagues in many disciplines, such as natural sciences, engineering, humanities and social sciences, to solve the problem jointly. As soon as possible, we will give a comprehensive, systematic and in-depth contribution to the rich and profound meaning of Beautiful China. Furthermore, correct theoretical views and effective policy suggestions on how to build a Beautiful China should be given by us.

\section{HOW TO BUILD A BEAUTIFUL CHINA?}

After we then have a basic understanding and grasp of what a Beautiful China is, we have the goal of building it. Logically speaking, the "overall image" and "overall pattern" of a Beautiful China is mainly restricted within the overall goal of our ecological civilization construction field. The beautiful and harmonious ecological environment, which includes key areas (or key contents) and basic elements, has become our sub-goal of building a Beautiful China.

Carrying on this understanding paradigm, we need to focus on how to build a Beautiful China. As a strategic proposition and strategic task, it is manifested in a series of institutional and policy formulation, together with implementation issues.

\subsection{Set up a Beautiful China with Systematic and Complete System Thinking}

This complete institutional system, in the large section, includes the improvement of natural resources assets property rights system and relevant use.

The control system, the demarcation of the ecological protection red line, the implementation of the paid access system, the ecological compensation system, and the reform of the ecological environmental protection management system are considered here simultaneously.

Among them, in terms of improving the property rights system and the use control system of natural resources assets, there exists another sector: The institutional arrangements in the following key areas include the unified registration of natural ecological spaces such as water flow, forests, mountains, grasslands, wasteland and shoal; together with the formation of a property rights system for natural resources assets with clear attribution, clear positions of power, and effective supervision and control; We will also improve the national system for managing natural resources assets, improving the system for regulating natural resources, exercising unified control over all territorial space uses, establishing a system for spatial planning; Apart from the above, we still should define the limits of control over the development of production, living and ecological space, implementing the use control, improving the systems for conservative and 
intensive use of energy, water and land.

Second, in delimiting the red line for ecological protection, we must unswervingly implement the system of functional zones and push forward the development in strict accordance with the orientation of functional zones. At the level of government's management, it is necessary to strengthen the leading cadres' departure audit on the natural resources, and establish a lifelong research system for ecological environmental damage. We will abolish the assessment of regional GDP in key counties with heavy poverty alleviation task, and some regions which have limited development areas and fragile ecosystems. At the technical level, an early-warning mechanism for monitoring the carrying capacity of resources and the environment should be established.

Third, in implementing the policies together with the paid access, use of resources and ecological compensation, we need to speed up the reform of the prices of natural resources and their products. Thereby, they could comprehensively reflect market supply and demand, resource scarcity, ecological environment damage costs, and restoration benefits as well. We insist on the principle of using resources to pay. We of course insist on the principle of who pollutes the environment and destroys the ecosystem, which will pay and compensate. Thus, the resource tax will gradually be extended to occupy various natural ecological spaces. In addition, we will promote the establishment of a horizontal ecological compensation system between regions, the development of environmental protection markets, the promotion of third-party environmental pollution control, institutional arrangements for effectively regulating the rational pricing mechanism for industrial and residential land, and raising the price of industrial land and other land areas. As we all know, these are very important and vital.

Finally, in the reform of the ecological environmental protection management system, we will establish and improve an environmental protection management system that strictly supervises the discharge of all pollutants, independently conduct environmental supervision and administrative law enforcement. A coordinated mechanism for regional coordination of ecosystem protection, restoration and pollution prevention should also be established, including controlling over land and sea. We will give more emphasis on the timely release of environmental information, the improvement of the reporting system, the strengthening of social supervision, and the improvement of the pollutant discharge permit system, the strict application of the compensation system to those responsible for environmental damage, the investigation of criminal responsibility in accordance with the law and other institutional arrangements reflecting the construction of ecological civilization. Ultimately, since ecological civilization is belongs to human activities, it's necessary and urgent to regulate and supervise on various actors.

\subsection{Ecological Civilization Construction's Involvement in Other Four Big Constructions}

It is vital to integrate the strategic task of China's civilization construction into four other relevant areas with Chinese characteristics, such as economic, political, social and cultural construction.

Theoretically, ecology itself is a system, usually referring to the whole of organisms and the surrounding environment (including light, heat, water, earth, etc.). For dimensions related to human activities, the ecosystem refers to all the connections between humans, the advanced animals that have language, can make tools and carry out production activities. It includes all the connections between humans and the non-living, and even living creatures around them. There is no doubt that the ecological civilization we are discussing here is more and more beautiful. The main thing is that we should not only make the living environment and non-living environment where we live harmonious, but also maintain their harmonious relations and contacts with people.

Since human activities include not only political and economic activities, but also social activities and cultural activities, how can we promote and maintain ecological harmony? It is necessary to integrate the relevant ecological environmental protection and ecological civilization into the political, economic, social and cultural fields, together with relevant processes.

However, how to integrate them is a major challenge to the construction of ecological civilization and Beautiful China. Of course, it is very difficult to find out ready-made answers to the 21st century's propositions from existing theories and experience. All of us need to think and work together.

Generally speaking, because institutions are the deep and fundamental driving force for system's evolution and development, we still need to set up systems and policies from the angle of effective integration and interactive development. This will help us to analyze and acquire effective systems or policies on the ecological civilization construction, Beautiful China construction and the other four constructions.

For example, the integration of ecological civilization into economic construction requires the optimization of industrial structure and the transformation of development patterns in order to effectively cooperate with the protection of the ecological environment. More specifically, in the adjustment of the industrial structure, we must focus on adjusting the expansion and distortion of the real estate structure, and strive to resolve the excessive expansion of the real estate inventory so as to inject positive impetus for ecological harmony. Looking at the domestic situation, it is no exaggeration to say that real estate development is unhealthy. Therefore, the construction of ecological civilization or Beautiful China will certainly become difficult.

Why? We know that real estate investment usually accounts for more than half of a country's total investment. The large and distorted real estate inventory means 
millions of high-rise buildings vacant. It consumes huge amounts of steel, huge quantities of cement, huge quantities of sand and stone, and huge amounts of wood and other civil construction materials. Behind this, it is also closely linked to the misuse of vast amounts of primitive natural resources such as trees cut down, hills flattened, and rivers drained. Compared with the ecological beauty of the early reform and opening up period (1978-1992), of course, it is not surprisingly that the ecological environment in which we live has been overwhelmed and unrecognizable over the years. From this classic example of industrial development, the message we have received is that "ecological environment protection, ecological civilization development and even the construction of a Beautiful China really need to be placed in the overall layout of socialist construction with Chinese characteristics. There is indeed a need to integrate Beautiful China construction into key area such as economic construction. Only by this way, we could find out relevant governance mechanisms and policy regimes. How to integrate the construction of beautiful China into the political construction? It is crucial to integrate related key indicators into the performance evaluation of government agencies and cadres at all levels. How to integrate it in the construction of the social? It is crucial to advocate social members to love environment, protect ecology, resist ecological pollution and destruction. However, the question of how to integrate ecological civilization construction into cultural construction requires us to establish, strengthen and practice a series of good ideas: for example, protecting ecological environment is glorious, and the pollution or destruction of ecological environment is shameful. We thus create a good ecological civilization, a positive and promising atmosphere of Beautiful China construction.

In view of the length, this article does not further develop how to integrate ecological civilization or Beautiful China into the concrete areas among the above four constructions. As for how to integrate ecological civilization or Beautiful China construction into the process of new type of urbanization road, it is also another proposition that deserves high attention.

Actually, the new type urbanization with Chinese characteristics is just the ecological urbanization. This is an inevitable choice to abandon the old urbanization road previously and embark on a new type of urbanization road. The new type urbanization is necessarily an urbanization in which people live in harmony with nature, and people live in harmony with the ecological environment. To integrate ecological civilization or Beautiful China construction into a new type of urbanization, we must fully integrate the idea of ecological civilization into the process of new type urbanization development at first. Meanwhile, we focus on promoting energy conservation, emission reduction, green development, circular development and low-carbon development, including conserve intensive use of land, water and energy resources. We will strengthen environmental protection and ecological restoration, reducing interference with and damage to nature, promoting green development and low-carbon production, advocating green lifestyle behavior and an operational management model for urban construction. Apart from these, we must effectively eliminate ecological crises such as soil pollution, water pollution and frequent smog. Ultimately, the vast area over urban and rural China will inevitably become clearer, much pure, bluer, greener and more beautiful on the whole

\section{CONCLUSION AND MAIN BODY OF CONSTRUCTION}

In the strategic field of Beautiful China construction, in addition to the above two questions, there is still another proposition: who will build Beautiful China?

Some comrades have carried out this "questioning" more specifically as the main body of construction. Some point out that the party committee and government is the main body for building a Beautiful China. This answer may be more obvious. It seems to be clear that since the people are the creators of history, they should also be the practitioners and creators of the strategic cause of building a Beautiful China. That is to say: people should be the practitioners and creators of ecological environment construction within the vast territory of China. Of course, this great task of practicing, building, creating new ecological civilization or creating a new Beautiful China has been gradually accelerated under the leadership of the Party and the government. Obviously, it is not appropriate to simply say that the party and the government are the main body during the construction of a Beautiful China. Whereas, this subjective judgment proposition can be expressed as follows: the party and the government, together with the broad masses under their leadership are the main body for the construction of a Beautiful China.

\section{REFERENCES}

[1] Fen, S. U. N. "The Path Selection of Ecological Institutional Improvement in China from the Perspective of Ecological Civilization [J]." Yuejiang Academic Journal 5 (2012).

[2] Tiejun W, Kinchi L, Cunwang C, et al. Ecological civilization, indigenous culture, and rural reconstruction in China[J]. Monthly Review, 2012, 63(9): 29-35.

[3] Hu Y J. Ecological Civilization Construction in China: Origins, Concepts and Paths[J]. Applied Mechanics and Materials, 2014: 1810-1816.

[4] Junren W. The philosophical wisdom and action implications of "Beautiful China" [J]. Social Sciences in China, 2013, 34(4): 143-153.

[5] Marinelli, Maurizio. "How to Build a 'Beautiful China' in the Anthropocene. The Political Discourse and the Intellectual Debate on Ecological Civilization." 
Journal of Chinese Political Science 23.3 (2018): 365-386.

[6] Wei, Zhang, Li Hulin, and An Xuebing. "Ecological civilization construction is the fundamental way to develop low-carbon economy." Energy Procedia 5 (2011): 839-843.

[7] Xiao-guang, W. A. N. G. "Constructing a Beautiful China under the Idea of Ecological Civilization [J]." Journal of Beijing Normal University (Social Sciences) 2 (2013): 19-25.

[8] Zhang, Xiaohong, et al. "Evaluating the trends of China's ecological civilization construction using a novel indicator system." Journal of Cleaner Production 133 (2016): 910-923. 